\title{
Role of CT and MRCP in Evaluation of Biliary Tract Obstruction
}

\author{
Anagha Joshi - Kishore Rajpal · Ketan Kakadiya • \\ Ashank Bansal
}

Published online: 26 September 2014

(C) Springer Science+Business Media New York 2014

\begin{abstract}
Obstructive jaundice which is caused by bile duct obstruction can be clinically and biochemically indistinguishable from cholestatic jaundice caused by hepatocellular disease. The management of both these conditions being radically different, the principle task of the radiologist is to differentiate between hepatocellular and obstructive jaundice, using available imaging modality and help in further management. With the availability of non-invasive modality like computed tomography and magnetic resonance imaging (MRI), it is possible to diagnose obstructive jaundice early and accurately without any patient discomfort. The purpose of this article is to describe the protocol for evaluation of obstructive jaundice with use of MDCT and magnetic resonance cholangio pancreatography sequence of MRI and to describe the imaging features of the most common causes of obstructive jaundice like biliary calculi, bile duct strictures, choledochal cyst, gall bladder carcinoma, cholangiocarcinoma, primary sclerosing cholangitis, and pancreatic head carcinoma.
\end{abstract}

Keywords CT - MRCP - Obstructive jaundice - Biliary stricture $\cdot$ Cholangiocarcinoma $\cdot$ Choledocholithiasis

\section{Introduction}

Obstructive jaundice is a type of jaundice in which there is blockage of flow of bile from the liver to the intestine

This article is part of topical collection on Abdominal CT Imaging.

A. Joshi $(\bowtie) \cdot$ K. Rajpal · K. Kakadiya · A. Bansal

Lokmanya Tilak Munincipal Medical College \& Lokmanya

Tilak Munincipal General Hospital, Sion, Mumbai, India

e-mail: anaghajoshi2405@gmail.com resulting in redirection of excess bile and its by products like bilirubin into the blood. It can lead to complications like ascending cholangitis, hepatorenal syndrome, and malabsorbtion and hence requires urgent surgical intervention. The role of radiologist therefore is important in early diagnosis and in accurately delineating the level and the cause of obstruction, thus helping in staging as well as preoperative assessment of tumor respectability.

For long, Endoscopic Retrograde Cholangio Pancreatography (ERCP) was the standard established procedure for evaluation of patients with obstructive jaundice. However, being an invasive procedure, it has an inherent complication rate of 3-9\% and mortality rate of $0.2-0.5 \%$ [1]. Due to significant advances in cross-sectional imaging, in particular the advent of magnetic resonance cholangio pancreatography (MRCP), ERCP currently has an almost exclusively therapeutic role.

Endoscopic Ultrasound (EUS), an adjunct procedure to ERCP, can be used to detect small distal biliary ductal calculi, for local staging of periampullary neoplasm and for guided fine-needle aspiration.

Ultrasonography (USG) can be used as initial imaging modality to diagnose the biliary obstruction but artifacts due to bowel gas, gall bladder and bile duct calculi, breathing artifacts and obesity brings it down in the list of imaging modality of choice in obstructive jaundice.

With recent advances in MDCT technology enabling faster acquisition in a single breath hold and upgraded software techniques for image reconstruction, MDCT is now more sensitive for determining the preliminary level and cause of obstruction. Due to sub-second acquisition and multiphasic approach, newer studies have further refined the role of MDCT in terms of specific diagnosis and staging of the pathology. Thus, single breath hold, multiphasic, sub centimeter iso-voxel scanning with post 
processing through volume acquisition, maximum intensity projections (MIPs), and multiplanar reformations (MPR) all help to increase the diagnostic accuracy, which is immensely helpful in

a) Differentiating benign from malignant stricture.

b) Staging complex biliary malignancies in terms of involvement of biliary confluence, invasion, and encasement of the adjacent major arterial and venous channel rendering it inoperable, as well as regional lymphadenopathy and hepatic metastasis.

Hence, Multiphasic MDCT of the abdomen with pancreatic and venous phase through the hepatic-biliary-pancreatic region is now the accepted worldwide protocol for pancreatico-biliary malignancies.

Magnetic resonance (MR) imaging besides being noninvasive has the advantages of allowing detailed evaluation of the pancreatico-biliary tract with a large field of view (FOV), excellent patient tolerance, and three-dimensional (3D) data sets that can be cholangio-pancreatico graphically displayed. Two unique properties of bile that are exploited to produce MRCP images are its relatively high water content $\&$ stasis of bile, in comparison with the blood flowing through adjacent vessels in the portal tract [2•], producing projection images like ERCP. Hence, MRCP has virtually replaced ERCP as the primary investigative modality in all cases of obstructive jaundice not requiring early endoscopic intervention.

\section{Method of Evaluation}

\section{MRI}

In newer MRI machines, with state of the art imaging capability, MRCP can be performed either without the use of contrast agent or with the usage of contrast agent showing biliary excretion.

\section{Non-contrast MRCP}

Non-contrast MRCP technique is based on heavily T2 weighted sequence which can be performed in twodimensional (2D) or 3D modes [3•]. It shows increased signal from bile and pancreatic duct (PD) fluid and suppresses signal from background tissues such as solid organs and moving blood $[4,5]$. The imaging obstacles of long acquisition times and respiratory motion artifacts have largely been overcome with technical innovations such as short-breath-hold T2-weighted acquisitions, parallel imaging, and sophisticated respiratory triggering mechanisms. The parameters we used for non-contrast MRCP sequence in our institute are as follows (Table 1).

\section{Contrast MRCP}

Contrast-enhanced MRCP is based on the principle of selective excretion of liver specific, gadolinium-, and magnesium-based MR contrast media by the liver into the biliary system, in 10-60 min [6]. These excreted contrast media cause $\mathrm{T} 1$ shortening of the bile, resulting in hyperintensity on $\mathrm{T} 1 \mathrm{w}$ sequences. The liver-specific contrast agents are gadobenate dimeglumine (Gd-BOPTA), gadoxetic acid disodium (gadoxetate disodium, or Gd-EOBDTPA), and mangafodipir trisodium (Mn-DPDP). In our institute, the most commonly used sequence for contrast MRCP is e-THRIVE (fat-saturated T1 weighted fast gradient sequence), which can be acquired in a single breath hold of 20-22 s, reducing the breathing-related artifact. The main indication of contrast MRCP is in evaluation of biliary leak, which can occur either due to iatrogenic trauma or at the site of anastomosis in case of liver transplantation. Contrast MRCP gives advantage over noncontrast MRCP in determining the exact site of leak and in giving information about the communication of this leak with surrounding collection, if any. However, being gadolinium-based technique, it suffers from the inherent complications related to gadolinium like risk of nephrogenic systemic fibrosis in patients of renal failure and allergic reactions [7]. The other disadvantage is longer scan duration to obtain significant concentration of gadolinium in the biliary system.

\section{Advantage of $3 \mathrm{~T}$ Over $1.5 \mathrm{~T}$}

The signal to noise ratio (SNR) at $3.0 \mathrm{~T}$ is twice that at $1.5 \mathrm{~T}$, producing higher-resolution image data sets with reduced acquisition times. The visualization of arborization

Table 1 Imaging protocol for MRCP on 3T philips machine

\begin{tabular}{|c|c|c|c|c|c|c|c|}
\hline Sr. No. & Sequence & $\begin{array}{l}\text { Respiratory } \\
\text { compensation }\end{array}$ & TR & TE & $\begin{array}{l}\text { Slice } \\
\text { thickness }\end{array}$ & Matrix & Comment \\
\hline 1) & MRCP_3D & Navigated free breathing & 2,500 & 740 & $2 / 1 \mathrm{~mm}$ & $256 \times 256$ & $\begin{array}{l}\text { Gives source image and 3D MIP image } \\
\text { of pancreatic-biliary system }\end{array}$ \\
\hline 2) & $\begin{array}{l}\text { MRCP thick slab } \\
\text { (coronal) }\end{array}$ & Breath hold & 9,500 & 740 & $40 \mathrm{~mm}$ & $256 \times 256$ & $\begin{array}{l}\text { Gives 2D projection image of } \\
\text { pancreatic-biliary system }\end{array}$ \\
\hline
\end{tabular}


of intrahepatic ducts, bile duct variations, delineation of the PD particularly its side branches, and relation of the pancreatic parenchyma to the ductal system is better obtained at $3.0 \mathrm{~T}$ than at $1.5 \mathrm{~T}$. Also signal from fluid in the gastrointestinal tract is more effectively suppressed at $3.0 \mathrm{~T}$. Use of parallel imaging reduces acquisition time and hence reduces breathing-related artifacts. All this encourages the use of this modality for specific diagnostic applications like in diagnosis of primary sclerosing cholangitis [8].

\section{CT}

In our institute, plain abdominal CT is obtained at $120 \mathrm{kV}$, $200 \mathrm{mAs}$ to determine baseline HU value and to visualize any biliary calculi containing calcium. To determine post contrast enhancement, $90 \mathrm{ml}$ of non-ionic iodinated contrast $(350 \mathrm{mg} \% \mathrm{v} / \mathrm{w})$ is injected intravenously at a flow rate of $3 \mathrm{ml} / \mathrm{sec}$ with the aid of pressure injector (Mallinckrodt). Arterial and venous phase are taken at an interval of 18-22 \& 60-65 s, respectively, from the time of contrast injection. Delayed phase is taken after 10-15 min. Delayed phase is particularly important in cases of cholangiocarcinoma which show increased contrast enhancement as compared to normal surrounding parenchyma. 3D reconstruction with thin planar $(1 \mathrm{~mm})$ and MPR is performed in coronal and sagittal planes for better depiction of intraluminal and wall lesions of biliary tract.

\section{Normal Anatomy of Pancreato-Biliary System in MRCP (Fig. 1)}

Bile plays an important role in intestinal absorption. It is secreted by the liver and is transported into the duodenum through the biliary system. There is significant variation seen in the biliary tree, with normal biliary anatomy seen only in 50-60\% of the population. Hence, the basic knowledge of its normal anatomy and its variant is important to differentiate from the pathology. Biliary system consists of intrahepatic and extrahepatic components. The intrahepatic component is formed by various biliary radicles draining the respective hepatic segments. Biliary radicles draining segments $\mathrm{V}$, VIII form right anterior bile duct which is oriented vertically, and biliary radicles draining segment VI, VII form right posterior bile duct which is oriented horizontally. These right anterior and posterior bile ducts combine to form right hepatic duct (RHD). Biliary radicles draining segments II, III, and IV form left hepatic duct (LHD). The LHD and RHD combine together to form the common hepatic duct (CHD). Segment $\mathrm{I}$ is drained by separate biliary radicles draining in the angle of RHD \& LHD. The extra-hepatic biliary system consists of CHD \& common bile duct (CBD). CHD and cystic duct combine together to form the CBD. Both CBD and common hepatic artery are seen anterior to the portal vein, with $C B D$ on the right and hepatic artery on the left. CBD normally measures $5 \mathrm{~mm}$ up to 50 years of age and shows an increment of $1 \mathrm{~mm}$ per decade. Pancreas is drained by PD which is embryologically derived from the fusion of the ventral duct of Wirsung (major PD) and the dorsal duct of Santorini (minor PD). Non-fusion of these ducts forms most common variant called pancreatic divisum seen in up to $14 \%$ of population. The PD and CBD join together in the medial wall of D2 segment of duodenum forming a common channel. The terminal segments of CBD, PD, and this common channel are surrounded by a smooth muscle, called sphincter of Oddi.

\section{Biliary Calculi}

Cholelithiasis is a common cause (Table 2) of acute abdominal pain due to calculus cholecystitis and is one of the main indications for cholecystectomy. Cholelithiasis is twice more common in females than males. $80 \%$ gall bladder calculi are composed of more than $50 \%$ cholesterol and are seen mainly in patients of obesity, diabetes, and undergoing rapid weight loss. The remaining $20 \%$ of calculi are bile pigment calculi mainly seen in patients of hemolytic anemia. Small calculus can cause biliary obstruction by its easy passage into the bile duct, or a recent passage of calculi can lead to benign distal CBD stricture (Fig. 2). Biliary obstruction can also be caused by a calculus that has impacted in the region of gall bladder neck and causes extrinsic compression of bile duct with
Fig. 1 a Schematic diagram and b MIP 3D MRCP sequence showing normal anatomy of pancreatico-biliary tract. $R H D$ right hepatic duct, $L H D$ left hepatic duct, $C H D$ common hepatic duct, $C B D$ common bile duct, $P D$ pancreatic duct, $D 2$ $2^{\text {nd }}$ segment of duodenum, $C D$ cystic duct
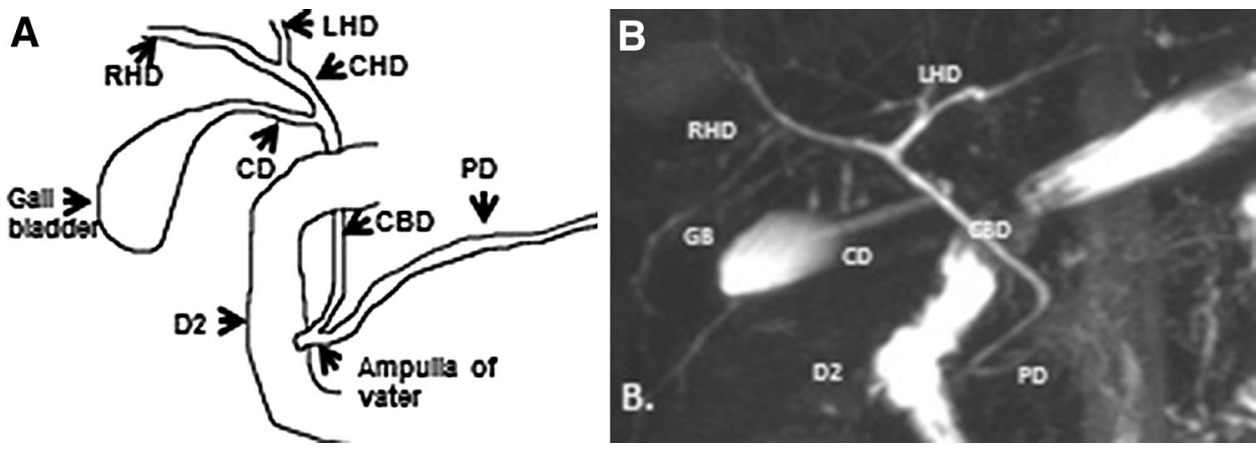
Table 2 Common causes of obstructive jaundice in both adult and paediactric age group

\begin{tabular}{ll}
\hline In adults & In pediatrics \\
\hline - Cholelithiasis (Mirizzi syndrome) and & $\bullet$ Biliary atresia \\
choledocholithiasis & $\begin{array}{c}\text { Choledochal } \\
\text { cyst }\end{array}$ \\
- Benign stricture & \\
- Choledochal cyst & \\
- Primary sclerosing cholangitis & \\
- Infection: \\
$\boldsymbol{\checkmark}$ bacterial cholangitis- and HIV-related \\
cholangiopathy, \\
$\boldsymbol{\checkmark}$ recurrent pyogenic cholangitis, \\
$\boldsymbol{\checkmark}$ parasitic disease \\
- Portal biliopathy \\
- Benign tumors of biliary tract \\
Malignant tumors causing obstruction of biliary \\
tract: \\
$\boldsymbol{\sim}$ Gall bladder carcinoma \\
$\boldsymbol{\sim}$ Cholangiocarcinoma \\
$\boldsymbol{\sim}$ Pancreatic head carcinoma
\end{tabular}

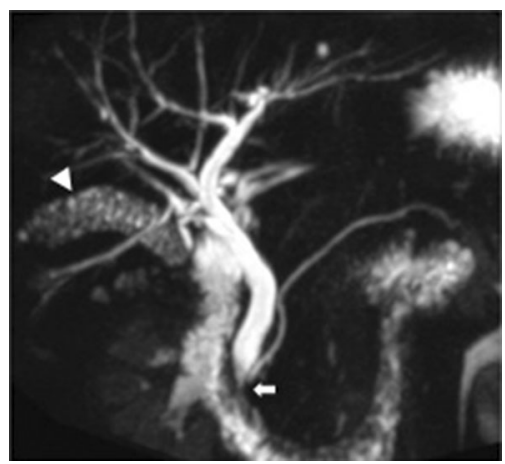

Fig. 2 MRCP 3D image showing a smooth short segment stricture (arrow) in the distal CBD due to recent passage of calculus. Gall Bladder is studded with multiple calculi manifesting as multiple filling defects (arrowhead)

resultant obstructive jaundice, this being known as Mirizzi's syndrome.

Magnetic resonance cholangio pancreatography is comparable to ERCP for the detection of choledocholithiasis and is superior to CT and USG, as it can detect calculi as small as $2 \mathrm{~mm}$ in size, which are seen as filling defects surrounded by T2 hyperintense bile (Fig. 3). For further characterization of stones, routine $\mathrm{T} 1$ and $\mathrm{T} 2$ weighted sequences are needed, on which pigmented stones appear hyperintense on $\mathrm{T} 1$ as compared to cholesterol stones which appear hypointense. Air bubbles are a common diagnostic pitfall but usually can be differentiated from stones by their smooth, rounded appearance and their tendency to cluster together and rise to the nondependent surface. At CT, biliary calculi can have
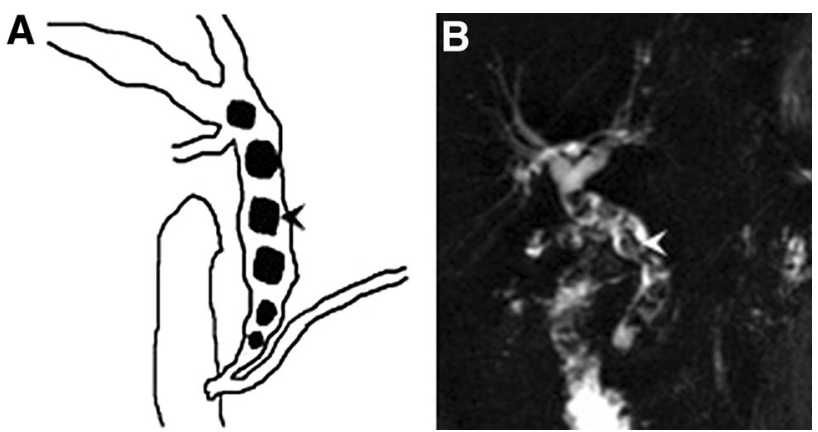

Fig. 3 a Schematic diagram, b single shot thick slab MRCP shows multiple well defined rounded filling defects (arrowhead) in a dilated CBD surrounded by $\mathrm{T} 2$ hyperintense bile s/o choledocholithiasis

variable appearance, ranging from highly calcified lamellated radio dense calculi to low-density calculi due to cholesterol content (Fig. 4). Air bubble can be easily differentiated from calculi on CT depending on its HU value. Local irritation caused by the stone or associated cholangitis may lead to findings of wall thickening, mucosal enhancement, and periductal fat stranding. However, in the presence of mural enhancement possibility of malignancy should be considered [9].

\section{Benign Biliary Stricture}

The major cause of benign biliary stricture is surgical trauma, other causes being gall stone, duodenal ulcer, and chronic pancreatitis. Incidence of post-operative stricture has increased in the recent period due to increase in number of laparoscopic procedures. Post-operative stricture can present month to years after the operation and mainly occurs due to ischemic or direct traumatic injury to the duct. Post inflammatory stricture like in case of choledocholithiasis, due to chronic irritation and inflammation, is seen manly in CBD and is short in length. Stricture due to chronic pancreatitis is seen in the region of pancreatic head and is usually $3-5 \mathrm{cms}$ in length.

The main concern while reporting benign stricture is to differentiate it from malignant stricture. While ERCP has been the gold standard for a long time for evaluation of strictures, a recent study by Park et al. in 2004 found MRCP to be more sensitive than ERCP. Sensitivity, specificity, and accuracy for the differentiation of malignant from benign causes of biliary stricture at MRCP were 81, 70, and $76 \%$ respectively, and at ERCP were 74, 70, and $72 \%$ [9].

Certain features can differentiate benign from malignant stricture. Features like wall thickness less than $1.5 \mathrm{~mm}$, length of stricture less than $9 \mathrm{~mm}$, and upstream bile duct dilatation of $<17 \mathrm{~mm}$ are more of suggestive of benign 
Fig. 4 Plain CT scan in axial (a) and reconstructed oblique coronal images (b) showing multiple gall bladder calculi (arrowhead) and impacted distal CBD calculus (long arrow) causing proximal dilatation of the bile duct (short arrow)
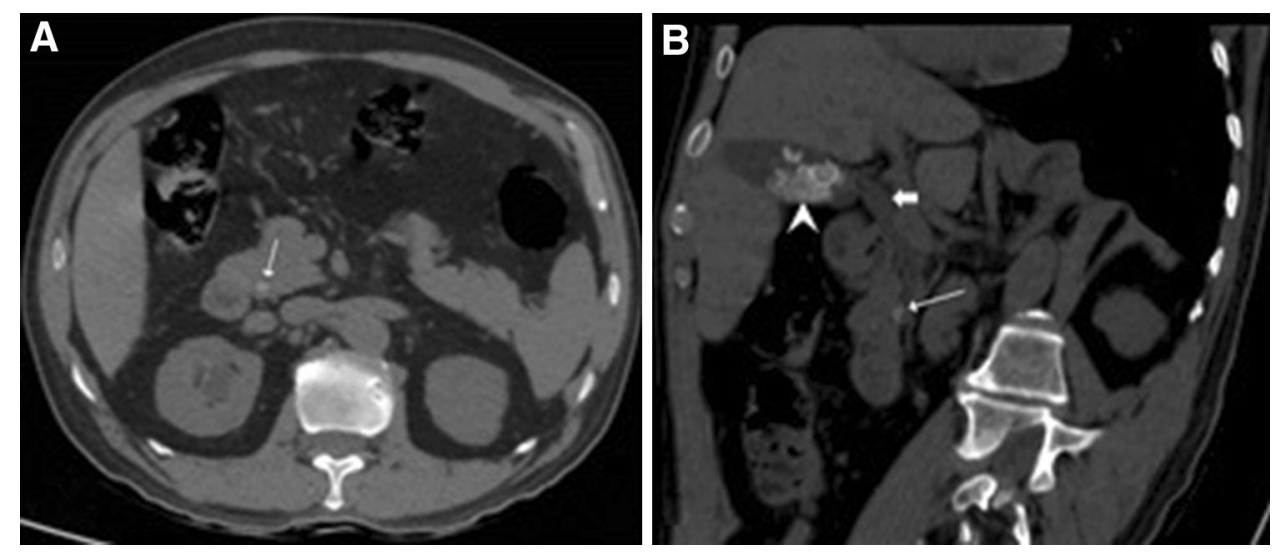
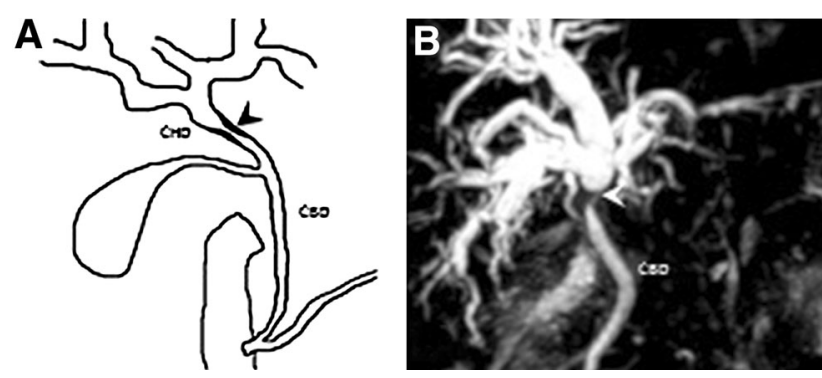

Fig. 5 a Schematic diagram and b MIP 3D MRCP showing short length benign stricture involving CHD (arrow head)

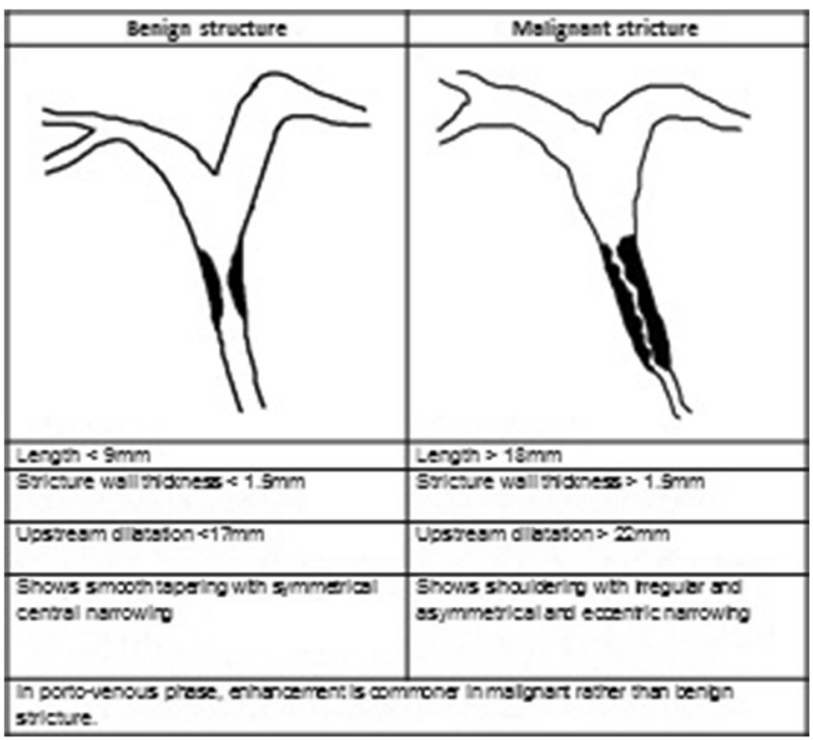

Fig. 6 Schematic diagram showing differentiation between benign and malignant stricture

stricture (Figs. 5, 6). MRCP finding of a dilated bile duct showing smooth and sudden tapering is diagnostic of postoperative biliary stricture. In addition, MRCP can accurately depict the anatomical level and length of stricture which is helpful in its operative management [10]. CT scan can show complications associated with stricture like cholangitis and associated abscess. Bismuth $\mathrm{H}$ [11] (Table 3) classified post-operative strictures into five types.

\section{Choledochal Cyst}

Choledochal cyst is a congenital anomaly involving biliary tree characterized by cystic dilatation of bile ducts manifesting usually after the age of 10 years. Clinically it is difficult to diagnose as most of the patients are asymptomatic. A classical triad of jaundice, pain, and right upper quadrant palpable lump, however, is seen in $30-60 \%$ of patients diagnosed before the age of 10 and in $10 \%$ of the cases diagnosed in adulthood [12].

Many theories exist regarding the patho-physiology of choledochal cyst, but the most accepted one is of anomalous pancreatico-biliary junction (APBJ). ABPJ is found in $10-58 \%$ cases of choledochal cyst (Fig. 7). Two features are considered responsible for the development of choledochal cyst; a length of more than $15 \mathrm{~mm}$ of the common channel formed after the union of PD and CBD outside the wall of duodenum and the angle of union between PD and CBD; both these features allowing reflux of pancreatic juice in the bile ducts causing their ectatic dilatation. Based on these two features, Komi et al. [13] classified APBJ into three types. In Type I, there is a right angle between the ducts, which is sub-classified into type IA (without dilatation) and type IB (with dilatation) of the common channel. In Type II, there is acute angle between the ducts which is also sub-classified into type IIA (without dilatation) and type IIB (with dilatation) of the common channel. Type III unions are defined by more complex patterns of accessory PDs.

Depending on the location and number of choledochal cysts, Todani et al. [14] (Table 4) classified choledochal cyst into five types as follows.

Type I choledochal cyst is the most common type. The complication associated with choledochalcyst is recurrent cholecystitis, choledocholithiasis, pancreatitis, 
Table 3 Bismuth classification of post-operative strictures

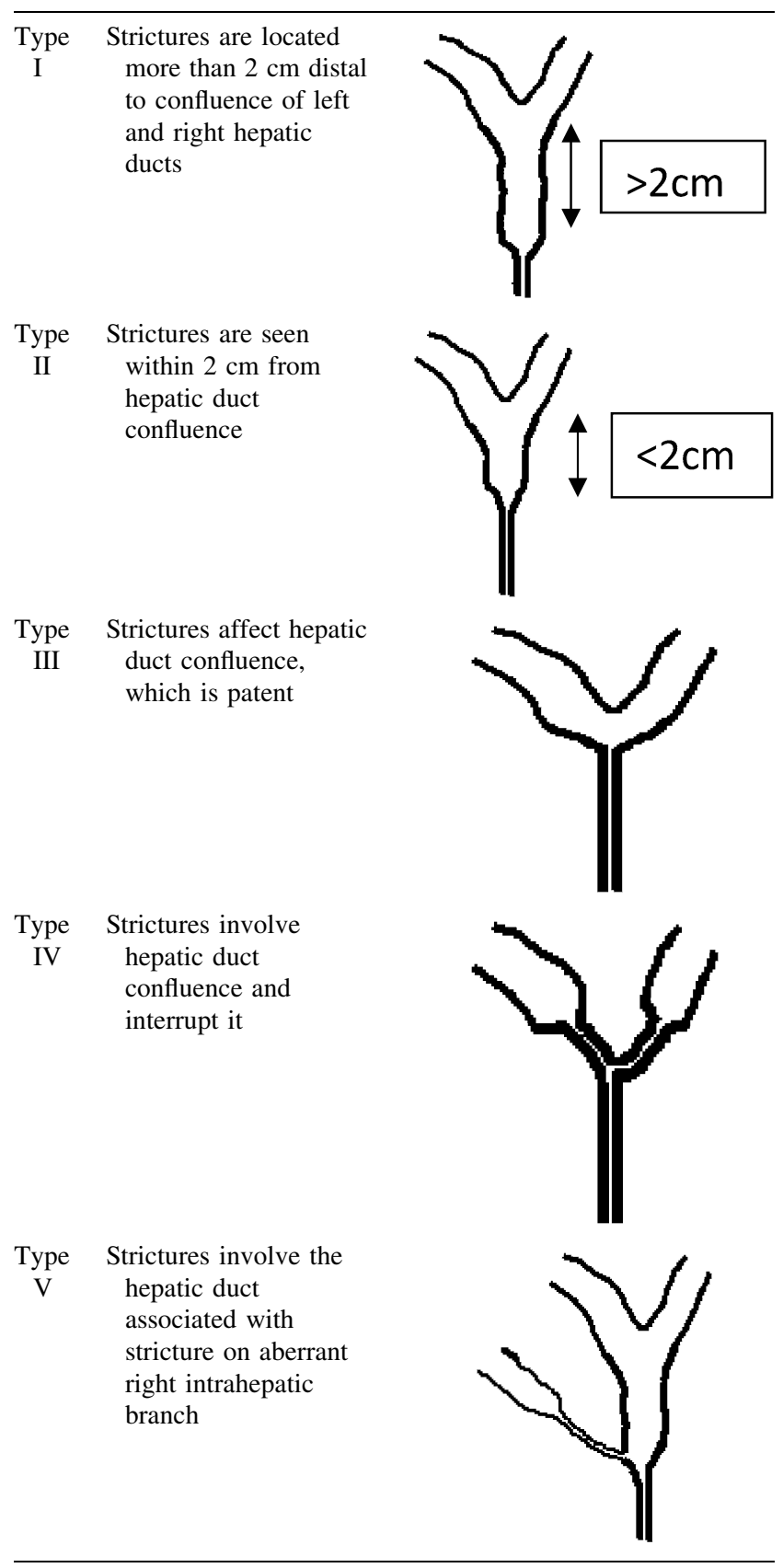

Table 4 Todani classification of choledochal cyst

\begin{tabular}{|c|c|}
\hline Type I & Dilatation confined to the extrahepatic bile duct \\
\hline IA & $\begin{array}{l}\text { Cystic dilatation of extrahepatic bile duct with gall } \\
\text { bladder arising from choledochal cyst }\end{array}$ \\
\hline IB & Focal or segmental dilatation of extrahepatic bile duct \\
\hline IC & Fusiform dilatation of extrahepatic bile duct \\
\hline Type II & True diverticula of the extrahepatic bile duct \\
\hline Type III & $\begin{array}{l}\text { Choledochocele; confined to the extrahepatic bile duct } \\
\text { within the duodenal wall }\end{array}$ \\
\hline Type IVA & $\begin{array}{l}\text { Dilatation involving both the extrahepatic bile ducts and } \\
\text { intrahepatic bile ducts }\end{array}$ \\
\hline Type IVB & Dilatation involving extrahepatic bile ducts \\
\hline Type V & Caroli's disease; cysts confined to the intrahepatic ducts \\
\hline
\end{tabular}

and malignant transformation to cholangiocarcinoma [15]. The role of imaging in choledochal cyst is to localize it, determine its relationship to adjacent structures, to evaluate the complications related to it, and look for any associated biliary tree abnormalities. USG can be used as initial screening modality however it may be difficult to evaluate the bile duct due to bowel gas.

On CT, it is seen as large cyst with fluid density in the region of porta communicating with bile duct. MRCP is an extremely useful tool for detection and classification of choledochal cysts (Fig. 8). It is particularly important in cases of patient with choledochal cysts associated with bile duct stricture, in which ERCP is suboptimal due to nonopacification bile duct distal to stricture [16].

\section{Gall Bladder Carcinoma}

Gall bladder cancer most often occurs in elderly women and is usually associated with gallstones (90\% of cases). Other risk factors include a chronic typhoid carrier state, choledochal cyst, gall bladder polyp, anomalous APBJ, and porcelain gallbladder. About $20 \%$ of patients with porcelain gallbladder develop gallbladder cancer. Gall bladder carcinomas are characterized by local invasion, extensive regional lymph node metastasis, vascular encasement, and
Fig. 7 a 3D MRCP b thick slab single shot MRCP showing focal dilatation of extra-hepatic bile duct (Type I B Choledochal cyst) (thick arrow) with anomalous pancreato-biliary junction (minor duct opening into CBD) (thin arrow)
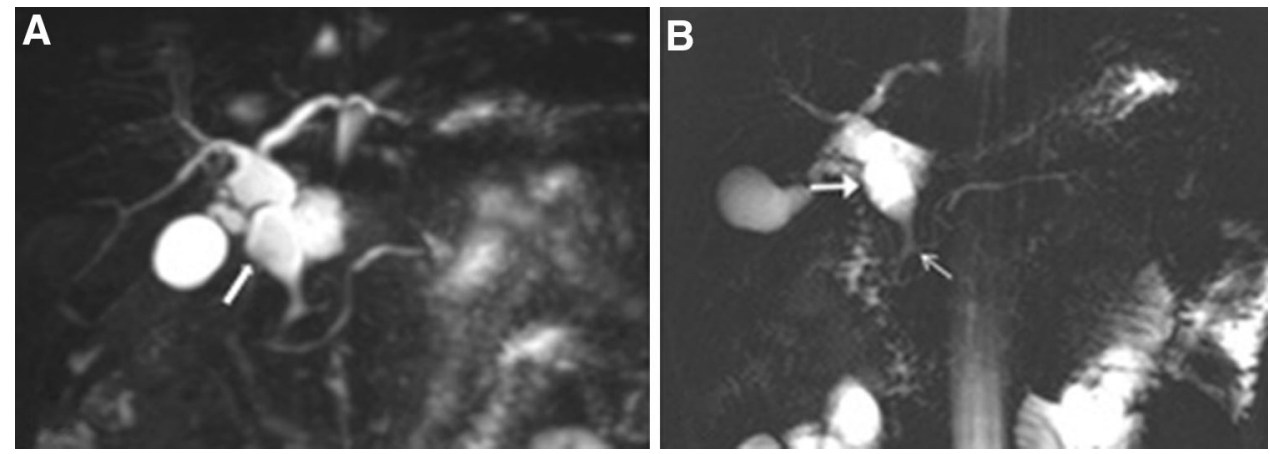
Fig. 8 a Schematic diagram of type 1C choledochal cyst. b Thick slab MRCP image of type IC choledochal cyst showing fusiform dilatation of extrahepatic bile duct (arrow) with normal intrahepatic bile ducts associated with complication as cholelithiasis with in dilated duct (arrow head)
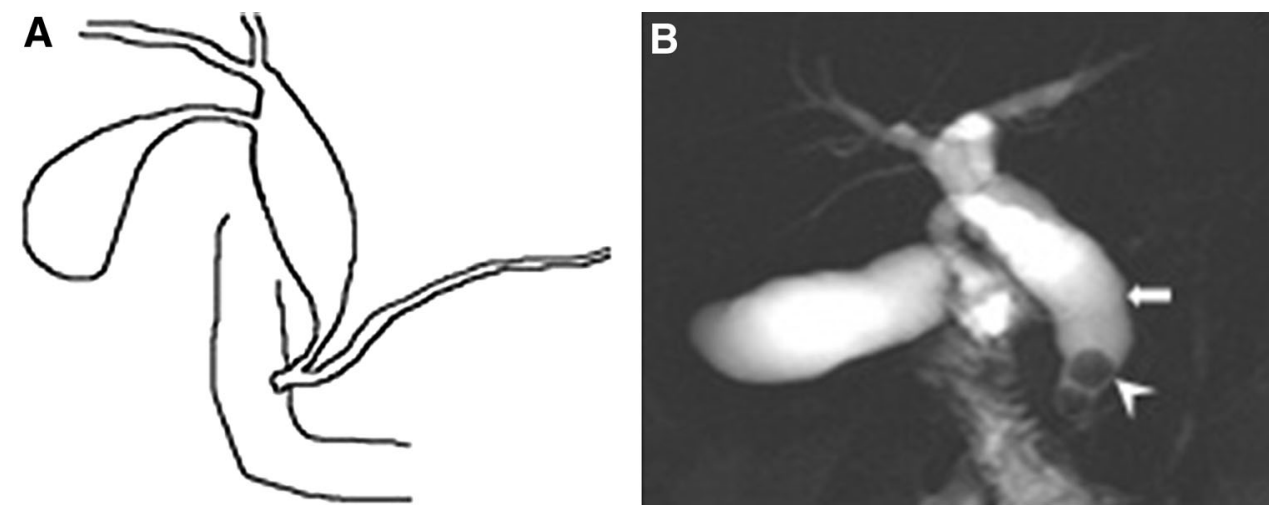
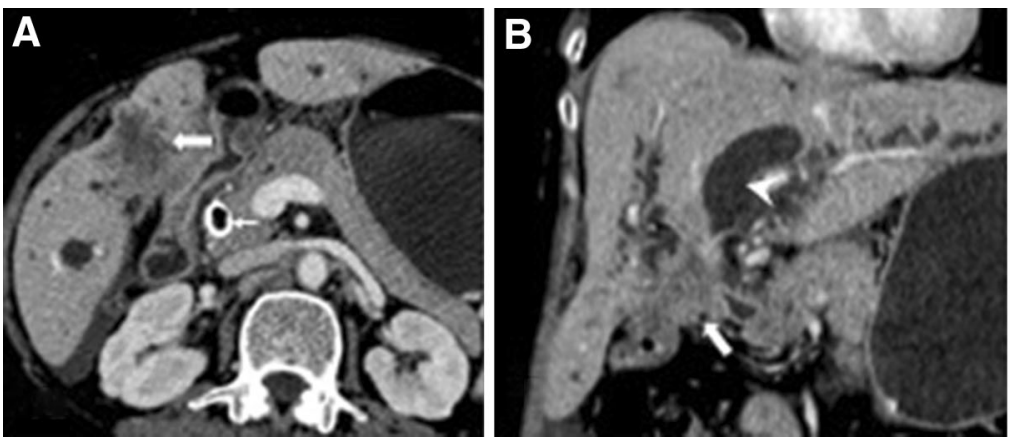

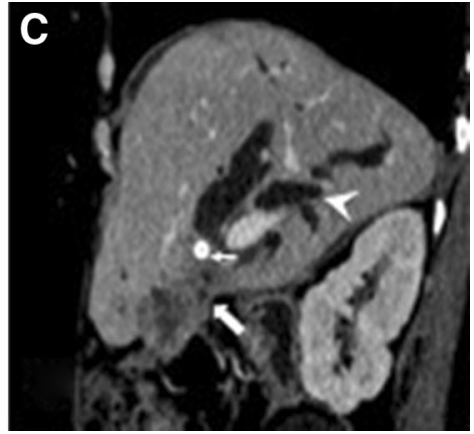

adjacent liver and porta causing intra-hepatic biliary dilatation (arrowhead). Metallic biliary stent noted in situ (thin arrow)

heterogeneously enhancing mass lesion replacing gall bladder in the region of gall bladder fossa (arrow) with localized invasion in the

distant metastases. In general, it is the most aggressive of the biliary cancers with the shortest median survival duration and requires early surgical intervention. Hence early diagnosis is crucial for patient management.

Obstructive jaundice can occur either due to invasion of gall bladder mass in the region of porta (Figs. 9, 10) or due to metastatic portal lymphadenopathy compressing the bile duct. Morphologically, gallbladder carcinoma can present as a mass completely occupying or replacing the gallbladder lumen, focal, or diffuse asymmetric gallbladder wall thickening or as an intraluminal polypoidal lesion [17]. Mass forming type is the most common, causing obstructive jaundice due to hilar extension [18].

On contrast-enhanced CT, gall bladder carcinoma is seen as an enhancing mass in the region of gall bladder fossa, asymmetric wall thickening or as an enhancing large $(>1 \mathrm{~cm})$ intraluminal polypoidal mass [18]. MDCT with multi-planar reconstruction helps in evaluation of local spread (in liver, hepatic flexure of colon, duodenum) vascular involvement, metastatic lymphadenopathy, and metastasis (liver, peritoneal) which help in staging and determining the resectability of tumor.

Magnetic resonance cholangio pancreatography helps in evaluation of hilar extension of mass forming type of gall bladder carcinoma, which is seen as intrahepatic bile duct dilatation on MRCP sequences. Intraluminal polypoidal type is seen as a lesion arising from the wall of gall bladder casing peripheral filling defect. However, gall bladder calculus can also produce similar filling defect, hence additional $\mathrm{T} 1, \mathrm{~T} 2 \mathrm{~W}$ and contrast images are required for confirmation of diagnosis.

\section{Cholangiocarcinoma}

Cholangiocarcinoma is a tumor arising from the bile duct epithelium and it can arise from anywhere along the bile duct.

Anatomically cholangiocarcinoma can be classified as $[19,20 \bullet]$

1) Intrahepatic (peripheral) arises from beyond secondorder bile ducts.

2) Perihilar (Klatskin tumors)-arises at the bifurcation of the hepatic ducts involving CHD and biliary ducts up to second-order bifurcation.

3) Extrahepatic-arising from CBD.

Morphologically, according to the Japanese Liver Cancer Group, tumor growth can be described as. 

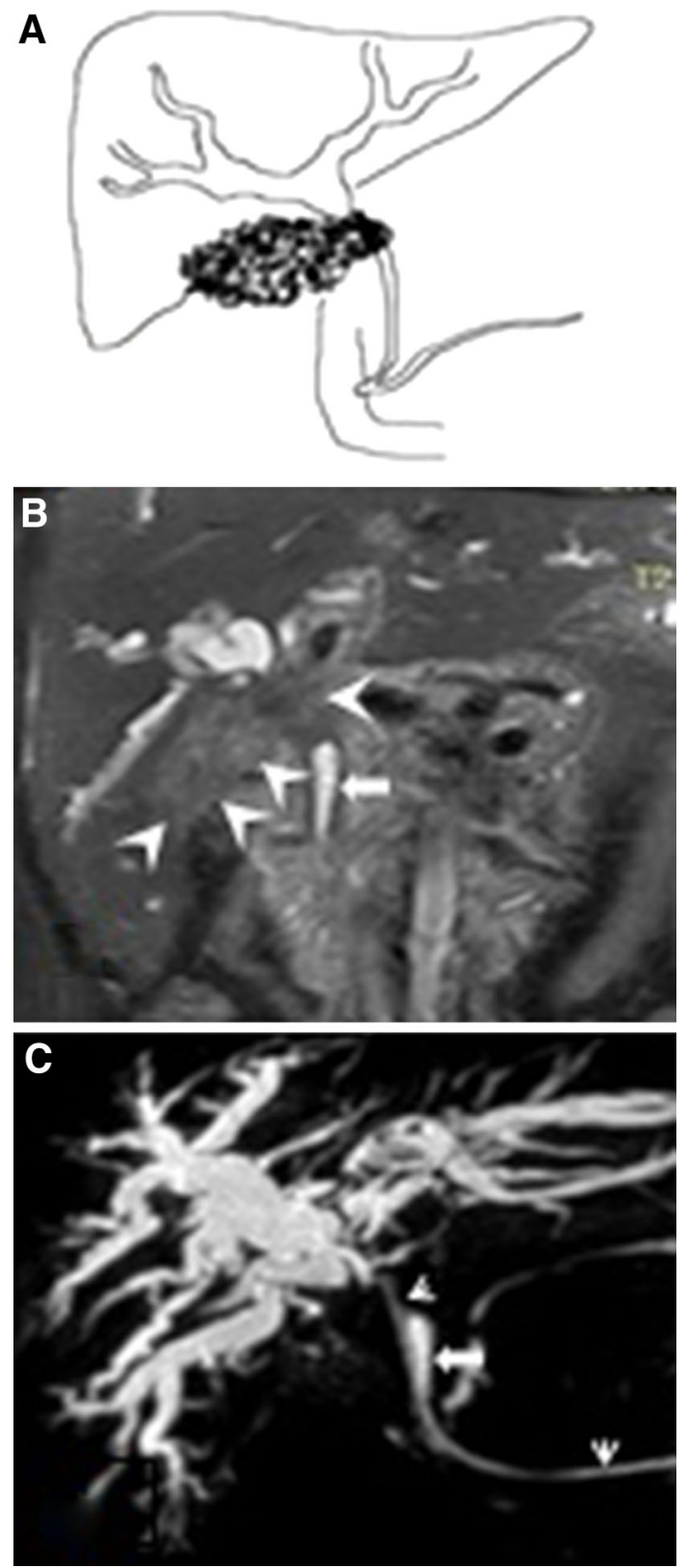

Fig. 10 Image a: schematic diagram of mass forming type of gall bladder carcinoma. Image $\mathbf{b}$ : T2 coronal image showing mass forming type of gall bladder carcinoma with local spread in hepatic hilum and involving CHD and part of CBD (arrow heads). Normal CBD is seen in the region of pancreatic head (arrow). Image c: MIP 3D MRCP sequence showing non visualization of gall bladder, CHD and part of CBD with intrahepatic bile duct dilatation. A thin linear T2 hyperintense structure in the region of CHD extending in the duodenal loop s/o biliary stent (arrow head). Normal CBD is seen in the region of pancreatic head

1) Mass-forming (exophytic)

2) Periductal (infiltrating) (Fig. 11)

3) Intraductal (polypoidal) (Fig. 12)

4) Mixed (mass forming and periductal) pattern.
Out of all the types of cholangiocarcinoma, perihilar is the most common type, presenting as jaundice and shows infiltrating pattern. Bismuth and Corlette classified perihilarcholangiocarcinoma (Klatskin tumors) depending on extent of ductal involvement (Table 5) (Fig. 13).

Apart from localization of level of obstruction and cause of obstruction, contrast-enhanced CT scan helps in determining the morphological type of cholangiocarcinoma, local spread, vascular involvement and determining stage and resectability of tumor. In cases of cholangiocarcinoma, delayed scan at $10-15 \mathrm{~min}$ is particularly important as it is shows delayed enhancement.

Magnetic resonance cholangio pancreatography plays vital role in evaluation of biliary tumors and has replaced ERCP and percutaneous transhepatic cholangiography (PTC) in many centers. The reported sensitivity and specificity of MRCP compared to ERCP for the detection of bile duct malignancy are 81 and $100 \%$ compared to 93 and $94 \%$, respectively [18]. The main advantage of MRCP over ERCP is that it can evaluate the extent of involvement and the dilated biliary tract beyond the level of obstruction which cannot be evaluated in ERCP due inadequate opacification of biliary tract distal to the obstruction [21, 22]. The main drawback of MRCP over ERCP is that it is only diagnostic.

The main feature of malignant biliary stricture on MRCP is long segment, irregular narrowing of biliary tract with upstream asymmetric dilation. The information which is required in the management of hilar carcinoma is the level of obstruction, extent of involvement, whether the involvement is up to primary or second-order branches and associated choledocholithiasis [23]; all can be obtained from MRCP images [22]. MRCP provides only endoluminal images from fluid, hence sometimes it could be inadequate to differentiate between benign and malignant stricture. In such cases, conventional $\mathrm{T} 2, \mathrm{~T} 1 \mathrm{~W}$ and contrast images give added advantage by visualization of malignant mass, metastasis, and metastatic lymphadenopathy.

\section{Primary Sclerosing Cholangitis}

Primary sclerosing cholangitis is an uncommon idiopathic inflammatory condition characterized by fibrosis of the biliary tree. As the disease progresses, it leads tocholestasis and in $49 \%$ of symptomatic patients finally to biliary cirrhosis and liverdamage. The risk of developing cholangiocarcinoma is $10-15 \%$ among primary sclerosing cholangitis patients. Young to middle age males around fourth decade are the most frequently affected. It is strongly associated with inflammatory bowel disease, most commonly ulcerative colitis.

The finding of wall thickening with dilatation of bile duct can be seen in CT however only these findings are not 
Fig. 11 a and b contrastenhanced coronal images of CT scan showing long segment enhancing wall thickening involving CHD and CBD (arrow head) with secondary upstream dilatation of intrahepatic bile ducts (arrow)
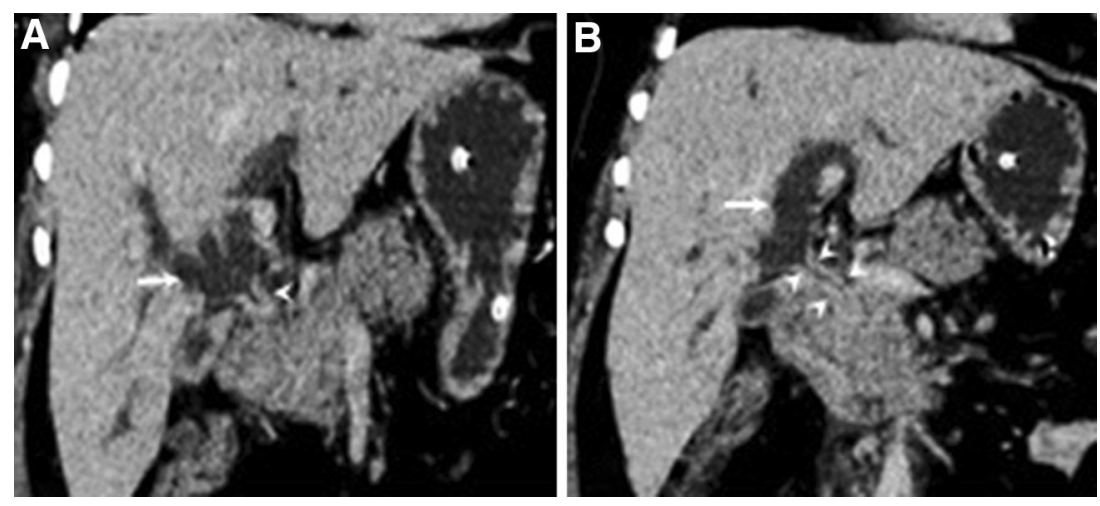

Fig. 12 Contrast-enhanced Axial, coronal, and sagittal planes in portal phase showing an enhancing endoluminal polypoidal mass (arrows) in the mid common bile duct, causing proximal biliary dilatation
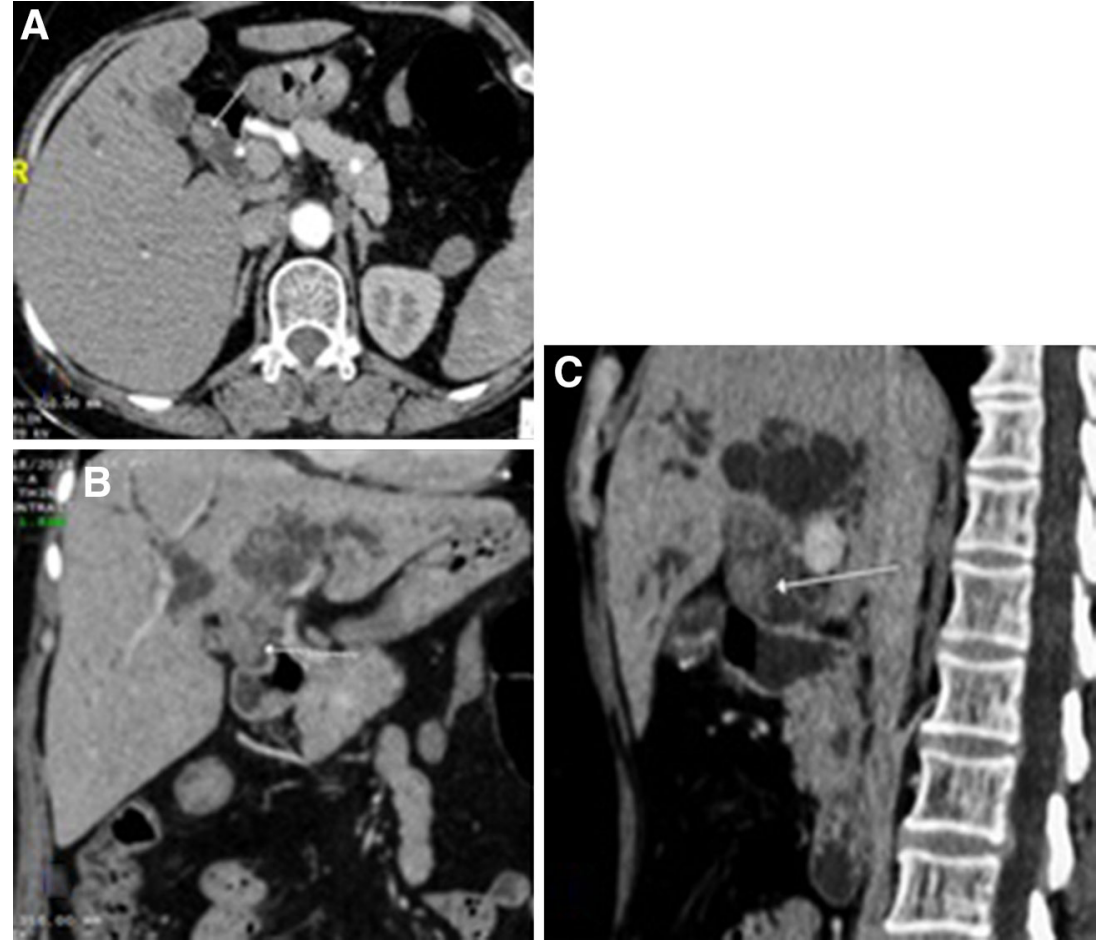

Table 5 Bismuth and Corlette classification of peri-hilar cholangiocarcinoma (Klatskin tumor)

Type I Tumor confined to CHD causing obstruction

Type II Tumor of the CHD bifurcation involving both main right and left hepatic ducts, and causing obstruction at the hilum with no communication between the main right and left hepatic ducts

Type IIIa Tumors extending into right secondary intrahepatic ducts, with absence of ductal obstruction on the contra-lateral side

Type IIIb Tumors extending into left secondary intrahepatic ducts, with absence of ductal obstruction on the contra-lateral side

Type IV Tumor involves the secondary and tertiary intrahepatic ducts in both lobes causing bilateral obstruction sufficient for diagnosis of PSC. In normal subjects on MRCP, only the central ducts containing adequate bile can be seen. Peripheral small biliary radicles are not seen as there is insufficient pressure to distend them. Multiple stricturous involvement of central bile ducts in PSC prevents contrast opacification of peripheral bile ducts, producing prune tree appearance on ERCP. However, because of generation of back pressure in these peripheral small bile ducts, they can be appreciated on MRCP giving an added advantage over ERCP. A study done by Fulcher et al. [24], found sensitivity of $88 \%$ for MRCP as compared to ERCP in diagnosis of PSC.

The characteristic finding of PSC is multiple alternating short segment strictures and slightly dilated intervening bile duct segments leading to bead on string 
Fig. 13 Schematic diagram and MRCP images of types of

Klatskin's tumors. Figure a, bType I cholangiocarcinoma, showing involvement of CHD with patent confluence. Figure c, d-Type II

cholangiocarcinoma, showing involvement of CHD and firstorder branches of RHD and LHD. Figure e, f-Type IIIA cholangiocarcinoma, showing involvement of CHD and of RHD up to its second-order branch. Figure g, h-Type IV cholangiocarcinoma, showing involvement of both right and left hepatic ducts up to their second-order branches
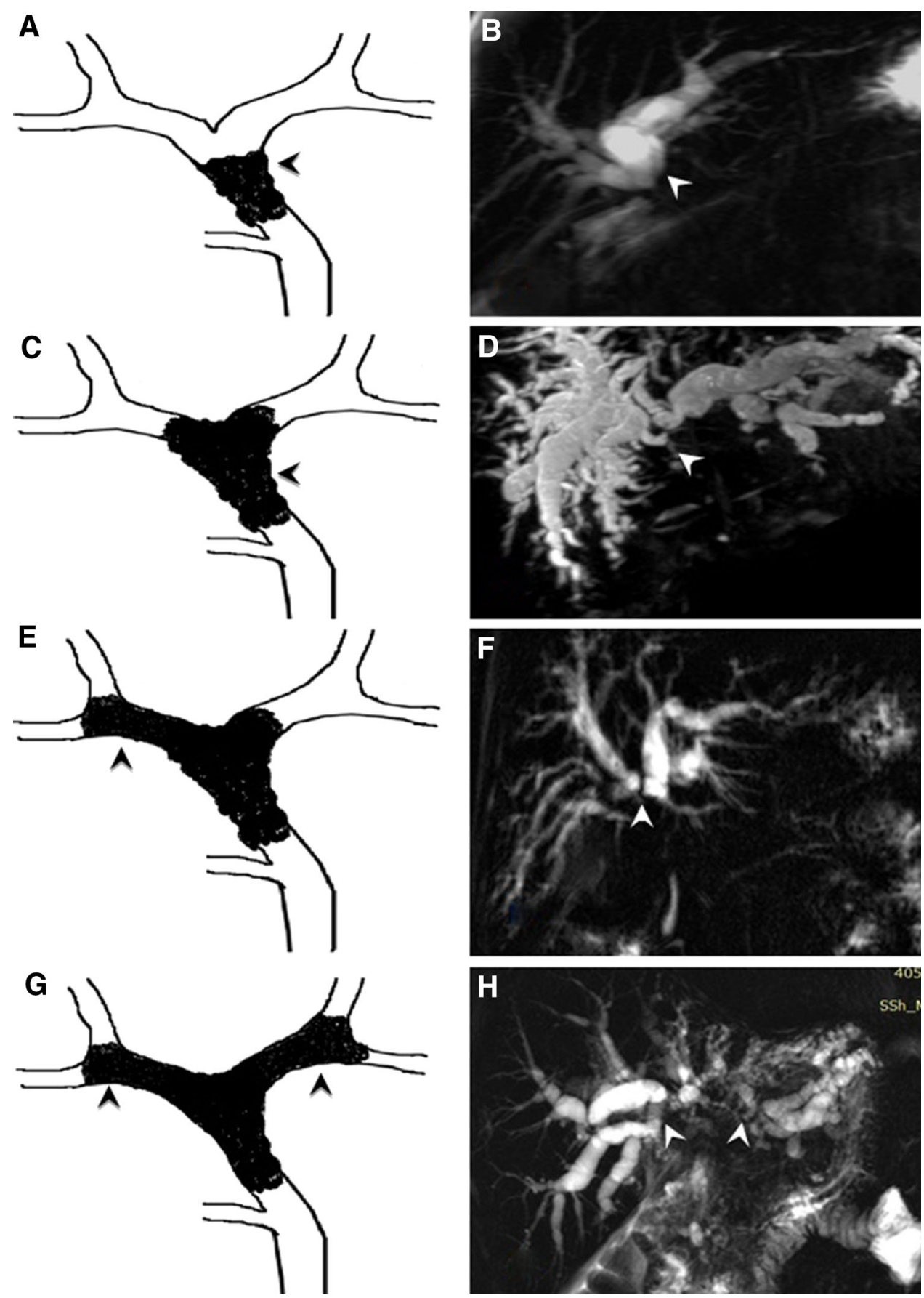

appearance (Fig. 14). In addition to this classical finding, formation of mural nodules, thickening of the duct wall, diverticula and webs, although not pathognomonic for primary sclerosing cholangitis, can be observed. Up to $27 \%$ of patients with primary sclerosing cholangitis have diverticula. Being non-invasive modality, it is particularly important for screening of such patients avoiding the complication related to invasive ERCP. Additional conventional $\mathrm{T} 1$ and $\mathrm{T} 2 \mathrm{~W}$ sequences also help in early diagnosis of the rare complication of cholangiocarcinoma related to $\mathrm{PSC}$.

Pancreatic Head Tumors

Cancer of pancreas is currently the ninth most common malignancy but represent the fourth most common cause of cancer-related death in the United States. In clinical practice, pancreatic tumor is synonymous with adenocarcinoma 
Fig. 14 a Schematic diagram and b single shot MRCP showing multiple strictures involving intra- and extrahepatic biliary tract (arrow heads) in case of primary sclerosing cholangitis
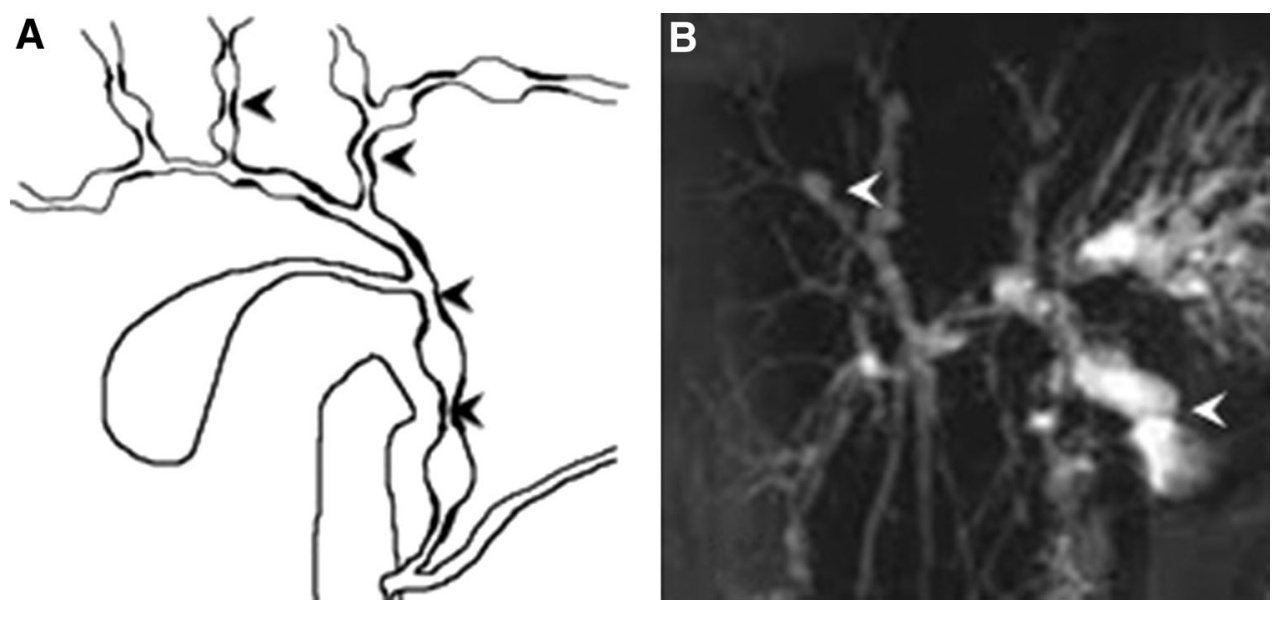

Fig. 15 a and $\mathbf{b}$ this patient is a 32-year-old lady with 6-week history of abdominal pain, intermittent vomiting, and jaundice. A contrast-enhanced multidetector CT scan showing lobulated minimally enhancing mass in the head of the pancreas, encasing the a long segment of the common bile duct (arrow) with the resultant proximal biliary dilatation (arrowhead)

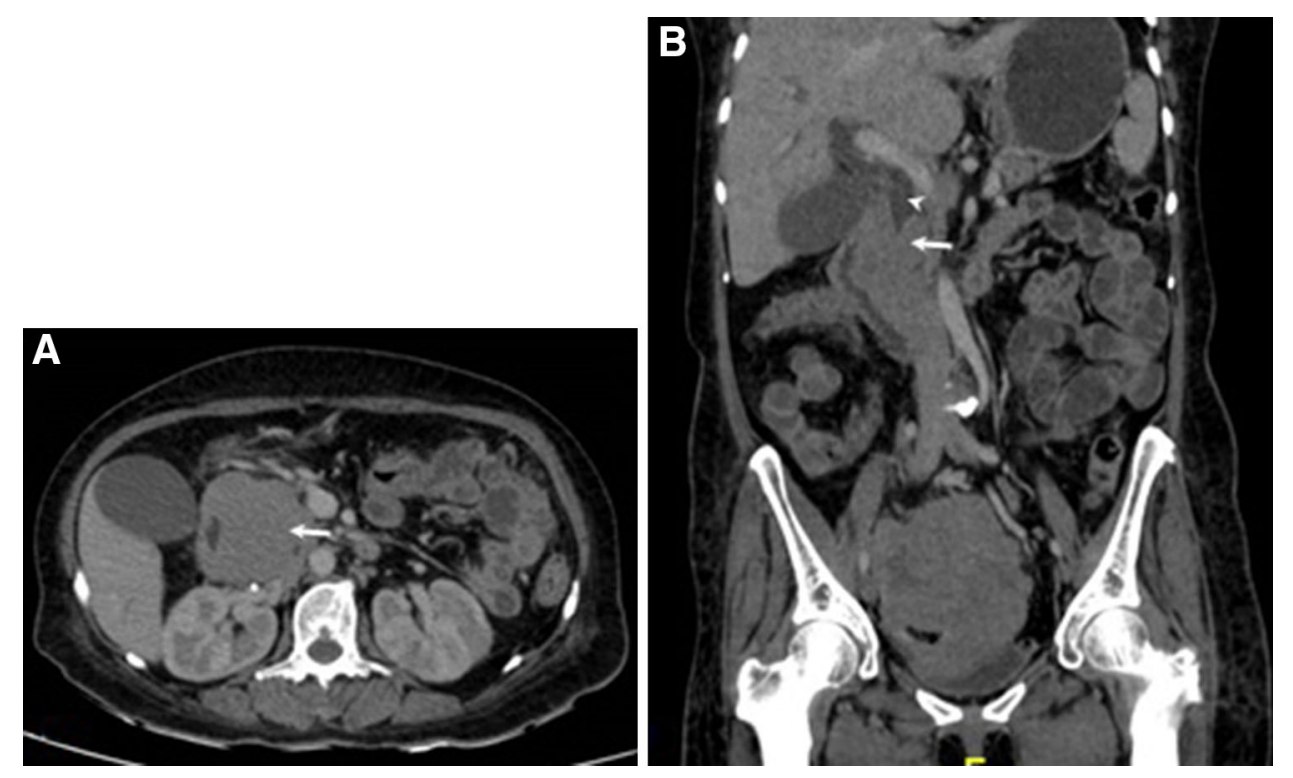

which accounts for $90-95 \%$ of cases. Up to $75 \%$ of cases, the tumor is located within the pancreatic head which can cause biliary obstruction. Pancreatic tumors are well known to present late leading to delayed diagnosis and poor prognosis. The role of imaging in pancreatic carcinoma is

1) Confirming the diagnosis.

2) Localizing the lesion.

3) Staging the tumor.

4) Determining the respectability.

5) Advising the surgeon preoperatively of relevant anatomical vascular variants.

Although multi-detector CT still plays an important role in local invasion and extent of bile duct obstruction, MRI has an advantage of tissue characterization with respect to few of the tumors like lympho-proliferative disorders
(Figs. 15, 16) showing diffusion restriction. The characteristic imaging finding on MRCP is of obstruction leading to dilatation of PD, common bile duct, or both. Dilatation of both ducts leads to double-duct sign (Fig. 17). Other finding suggestive of malignant cause is irregular narrowing of pancreatic and bile duct in the region of pancreatic head.

\section{Conclusion}

In this newer era of imaging where multiple imaging modalities ranging from simple radiograph to most advanced MRI are available, it is the role of radiologist to guide the clinician in selecting the right imaging modality and to answer the questions which are important in patient 
Fig. 16 a, b, and c T2 weighted fat-suppressed images in axial and coronal planes of the same patient in Fig. 16, showing intermediate signal intensity inhomogeneous soft tissue mass in the head of pancreas with encasement and narrowing of common bile duct (arrow) causing proximal duct dilatation. DWI images showing foci of diffusion restriction of the pancreatic mass

(arrowhead) with renal deposits (small arrow) representing a lymphoproliferative disorder. A lobulated soft tissue bowel mass is seen in the pelvis showing intermediate to hyperintense signal intensity on $\mathrm{T} 2 \mathrm{~W}$ fatsuppressed images (star)

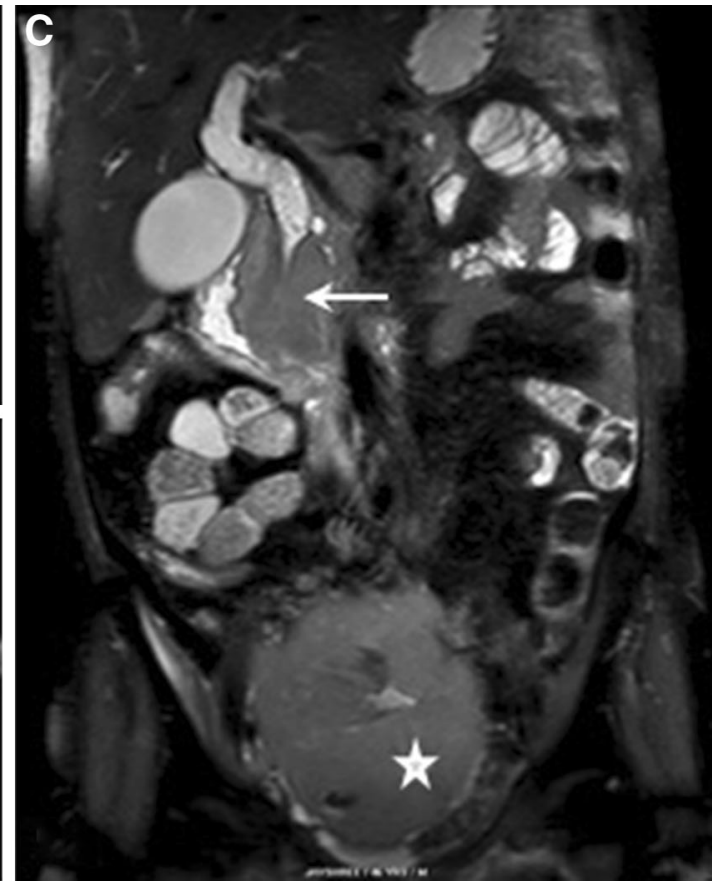

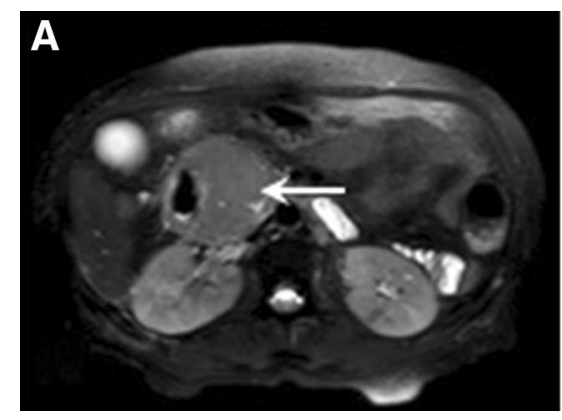
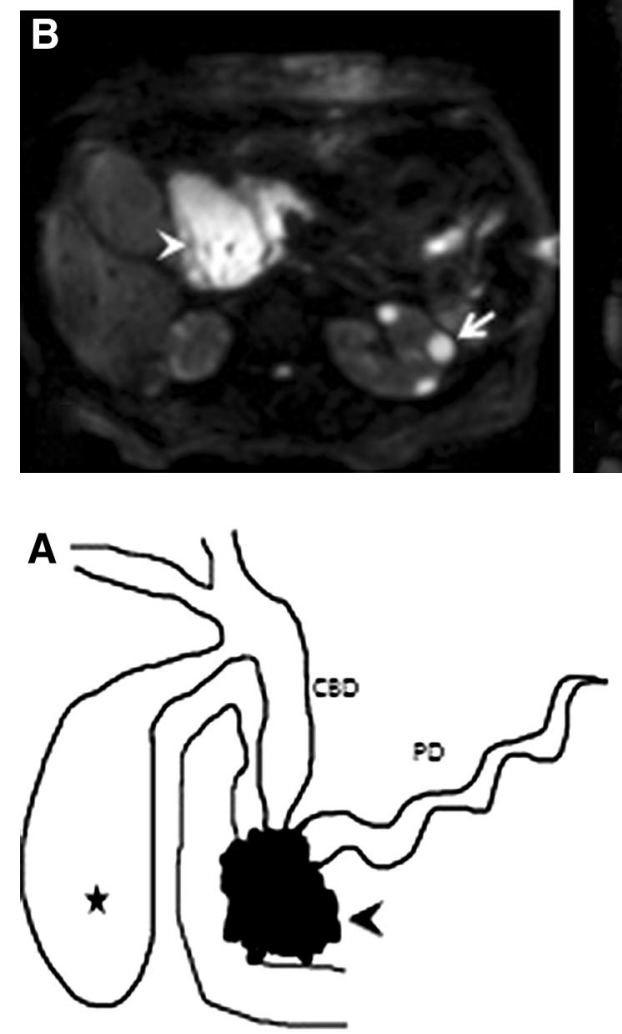

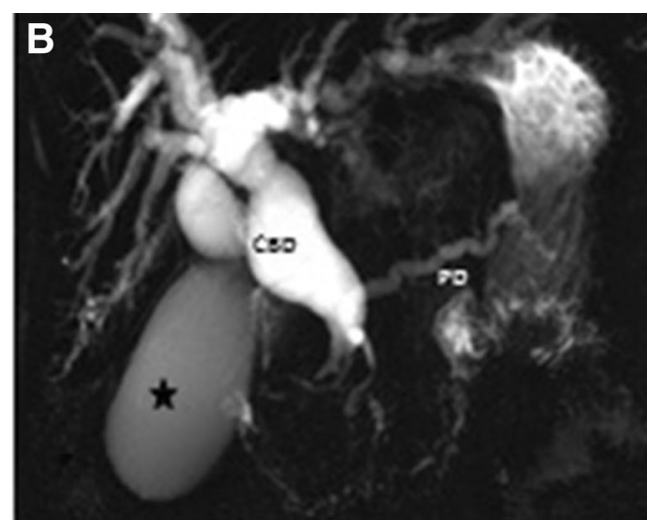

Fig. 17 a Schematic diagram and $\mathbf{b}$ single shot MRCP showing dilated $\mathrm{CBD}$ and $\mathrm{PD}$ (double-duct sign) in their entire extent with abrupt cutoff in the region of pancreatic head due to peri-ampullary tumor (arrow head) associated with over distended gall bladder(black star) management. Although ultrasound remains a screening modality for diagnosis of biliary obstruction, it is unable to answer the true extent and cause of obstructive jaundice requiring the use of another imaging modality like CECT and MRCP which scores over ultrasound in the diagnostic accuracy. MRCP can be considered as the new gold standard for the investigation of biliary obstruction and permits reservation of ERCP to patients with a high probability of therapeutic intervention.

\section{Compliance with Ethics Guidelines}

Conflict of Interest Dr. Anagha Joshi is a section editor for Current Radiology Reports. Dr. Kishore Rajpal, Dr. Ketan Kakadiya, and Dr. Ashank Bansal each declare no potential conflicts of interest.

Human and Animal Rights and Informed Consent This article does not contain any studies with human or animal subjects performed by any of the authors.

\section{References}

Recently published papers of particular interest have been highlighted as:

- Of importance

1. Rana SS, Bhasin DK, Sharma V, Rao C, Gupta R, Singh K. Role of endoscopic ultrasound in evaluation of unexplained common bile duct dilatation on magnetic resonance cholangiopancreatography. Ann Gastroenterol. 2013;26(1):66-70.

2. - Patel HT, Shah AJ, Khandelwal SR, Patel HF, Patel MD. MR cholangiopancreatography at $3.0 \mathrm{~T}$. Radiographics: a review publication of the Radiological Society of North America, Inc. 2009;29(6):1689-706. Describes and illustrates in detail 3.0T MRCP appearances of normal biliary tract anatomy, variants and benign and malignant pathologies.

3. - Yeh BM, Liu PS, Soto JA, Corvera CA, Hussain HK. MR imaging and CT of the biliary tract. Radiographics : a review publication of the Radiological Society of North America, Inc. 2009;29(6):1669-88. Gives good knowledge about the benefits 
and limitations of modern MR \& CT cholangiographic technique and the use of biliary specific contrast media.

4. Romagnuolo J, Bardou M, Rahme E, Joseph L, Reinhold C, Barkun AN. Magnetic resonance cholangiopancreatography: a meta-analysis of test performance in suspected biliary disease. Ann Intern Med. 2003;139(7):547-57.

5. Wallner BK, Schumacher KA, Weidenmaier W, Friedrich JM. Dilated biliary tract: evaluation with MR cholangiography with a T2-weighted contrast-enhanced fast sequence. Radiology. 1991; 181(3):805-8.

6. Yeh BM, Breiman RS, Taouli B, Qayyum A, Roberts JP, Coakley FV. Biliary tract depiction in living potential liver donors: comparison of conventional MR, mangafodipir trisodium-enhanced excretory MR, and multi-detector row CT cholangiography-initial experience. Radiology. 2004;230(3):645-51.

7. Marckmann P, Skov L, Rossen K, Dupont A, Damholt MB, Heaf JG, et al. Nephrogenic systemic fibrosis: suspected causative role of gadodiamide used for contrast-enhanced magnetic resonance imaging. J Am Soc Nephrol. 2006;17(9):2359-62.

8. O'Regan DP, Fitzgerald J, Allsop J, Gibson D, Larkman DJ, Cokkinos D, et al. A comparison of MR cholangiopancreatography at 1.5 and 3.0 tesla. Br J radiol. 2005;78(934):894-8.

9. Park MS, Kim TK, Kim KW, Park SW, Lee JK, Kim JS, et al. Differentiation of extrahepatic bile duct cholangiocarcinoma from benign stricture: findings at MRCP versus ERCP. Radiology. 2004;233(1):234-40.

10. Govil H, Reddy V, Kluskens L, Treaba D, Massarani-Wafai R, Selvaggi S, et al. Brush cytology of the biliary tract: retrospective study of 278 cases with histopathologic correlation. Diagn Cytopathol. 2002;26(5):273-7.

11. Bismuth H, Majno PE. Biliary strictures: classification based on the principles of surgical treatment. World J Surg. 2001;25(10):1241-4.

12. Marx FW Jr, Gray RK, Duncan AM, Bakhtiar L. Angiodysplasia as a source of intestinal bleeding. Am J Surg. 1977;134(1):125-30.

13. Komi N, Takehara H, Kunitomo K, Miyoshi Y, Yagi T. Does the type of anomalous arrangement of pancreaticobiliary ducts influence the surgery and prognosis of choledochal cyst? J Pediatr Surg. 1992;27(6):728-31.
14. Todani T, Watanabe Y, Narusue M, Tabuchi K, Okajima K. Congenital bile duct cysts: classification, operative procedures, and review of thirty-seven cases including cancer arising from choledochal cyst. Am J Surg. 1977;134(2):263-9.

15. Wiseman K, Buczkowski AK, Chung SW, Francoeur J, Schaeffer $\mathrm{D}$, Scudamore $\mathrm{CH}$. Epidemiology, presentation, diagnosis, and outcomes of choledochal cysts in adults in an urban environment. Am J Surg. 2005;189(5):527-31 discussion 31.

16. Park DH, Kim MH, Lee SK, Lee SS, Choi JS, Lee YS, et al. Can MRCP replace the diagnostic role of ERCP for patients with choledochal cysts? Gastrointest Endosc. 2005;62(3):360-6.

17. Levy AD, Murakata LA, Rohrmann CA Jr. Gallbladder carcinoma: radiologic-pathologic correlation. Radiographics. 2001;21(2): 295-314 questionnaire, 549-55.

18. Szklaruk J, Tamm E, Charnsangavej C. Preoperative imaging of biliary tract cancers. Surg Oncol Clin N Am. 2002;11(4):865-76.

19. Sainani NI, Catalano OA, Holalkere NS, Zhu AX, Hahn PF, Sahani DV. Cholangiocarcinoma: current and novel imaging techniques. Radiographics. 2008;28(5):1263-87.

20. • Chung YE, Kim MJ, Park YN, Choi JY, Pyo JY, Kim YC, et al. Varying appearances of cholangiocarcinoma: radiologic-pathologic correlation. Radiographics : a review publication of the Radiological Society of North America, Inc. 2009;29(3):683 700. Illustrates detail imaging appears of various type of cholangiocarcinoma on CT and MRI and recent advance in imaging of biliary tract.

21. Manfredi R, Masselli G, Maresca G, Brizi MG, Vecchioli A, Marano P. MR imaging and MRCP of hilar cholangiocarcinoma. Abdom Imaging. 2003;28(3):319-25.

22. Pavone P, Laghi A, Passariello R. MR cholangiopancreatography in malignant biliary obstruction. Semin Ultrasound CT MR. 1999;20(5):317-23.

23. Yeh TS, Jan YY, Tseng JH, Chiu CT, Chen TC, Hwang TL, et al. Malignant perihilar biliary obstruction: magnetic resonance cholangiopancreatographic findings. Am J gastroenterol. 2000; 95(2):432-40.

24. Fulcher AS, Turner MA. Orthotopic liver transplantation: evaluation with MR cholangiography. Radiology. 1999;211(3):715-22. 